\title{
INCIDÊNCIA DE CERCOSPORA SOJINA HARA EM CULTIVARES DE SOJA ( $\left.{ }^{(}\right)$
}

\author{
MARGARIDA FUMIKO ITO $\left({ }^{2,5}\right)$, MANOEL ALBINO COELHO DE MIRANDA $\left({ }^{3,5}\right)$, \\ CHRISTINA DUDIENAS $\left({ }^{2}\right)$, JOSE CARLOS VILA NOVA ALVES PEREIRA $\left({ }^{4}\right)$ \\ e EDUAARDO ANTONIO BULISANI $\left({ }^{3}\right)$
}

\begin{abstract}
RESUMO
Seis cultivares de soja foram avaliados em condiçoes de campo, com relação à mancha foliar "olho-de-râ" (Cercospora sojina Hara) em Ribeirão Preto (SP). Utilizou-se uma escala de notas de 1 a 5 , sendo 1 para infeç̧̃̃o mínima e 5 para infecção maxima. Os cultivares IAC-9 e IAC-10 apresentaram-se como suscetíveis, IAC-8 e IAC-12, como intermediários, e Cristalina e IAC-11, como resistentes. Mesmo nestes foram detectadas plantas suscetíveis. Diante desse fato e do risco potencial que esta moléstia pode apresentar, preconiza-se a eliminaçâo de plantas infectadas dos cultivares resistentes, principalmente em campos destinados à produçâ de sementes.
\end{abstract}

Termos de indexação: mancha foliar olho-de-rã; Cercospora sojina; soja, cultivares IAC-8, IAC-9, IAC-10, IAC-11 e IAC-12; resistência.

(1) Trabalho apresentado no XVII Congresso da Sociedade Brasileira de Fitopatologia, Sāo Paulo (SP), 9-13 de julho de 1984. Recebido para publicaçá em 18 de maio de 1984.

$\left({ }^{2}\right)$ Seção de Microbiologia Fitotécnica, Instituto Agronómico (IAC), Caixa Postal 28, 13100 Campinas (SP).

( $\left.{ }^{3}\right)$ Seção de Leguminosas, IAC.

(4) Estaçāo Experimental de Ribeirão Preto, IAC.

( $)$ Bolsista do CNPq. 


\section{INTRODUÇAO}

A mancha foliar "olho-de-rã", causada pelo fungo Cercospora sojina Hara, tem sido relatada ocasionando perdas na produção, em muitas regióes produtoras de soja. YORINORI \& GARCIA (1977) observaram, no Estado do Paraná, desde 1971, que campos do cultivar Bragg têm sofrido prejuízos quase totais.

Nos últimos anos, YORINORI (1984) verificou uma certa severidade da doença em cultivares suscetíveis no Planalto Central (Região do Alto Paranaíba, em Minas Gerais e no Sul de Goiás).

Em São Paulo não foi ainda citada alta incidência da doença. COSTA (1977) não obteve informação sobre sua distribuição no Estado nem sobre sua importância como causadora de perdas. Entretanto, como é considerável a parcela de sementes importadas dos Estados sulinos utilizadas para plantio no Estado de São Paulo, há o risco potencial de surtos epidêmicos da moléstia quando ocorrerem condiçoes ecológicas favoráveis ao patógeno.

Este trabalho teve por objetivo avaliar o comportamento de cultivares de soja quanto a Cercospora sojina, a campo, em local cuja ocorrência de sintomas em plantas suscetíveis é freqüente.

\section{MATERIAL E MÉTODOS}

O ensaio foi instalado na Estação Experimental de Ribeirão Preto, do Instituto Agronômico, numa área utilizada para ensaios com soja desde 1977. Foram testadas quatro épocas de plantio: 1 a: $25 / 10 / 1983 ; 2$ a : $16 / 11$ / 1983; 3a: 5/12/1983 e 4a: 27/12/1983, com seis cultivares: Cristalina, IAC-8, IAC-9, IAC-10, IAC-11 e IAC-12, com delineamento em parcelas subdivididas com quatro repetiçסes, sendo as épocas as parcelas e, os cultivares, as subparcelas.

Cada subparcela era composta por seis linhas de $6 \mathrm{~m}$ de comprimento, espaçadas de $0,6 \mathrm{~m}$, utilizando-se como adubação básica $350 \mathrm{~kg} / \mathrm{ha}$ do fertilizante de fórmula 0:18:6 $\left(\mathrm{N}, \mathrm{P}_{2} \mathrm{O}_{5}, \mathrm{~K}_{2} \mathrm{O}\right)$.

A avaliação das reaçōes dos cultivares foi realizada a 14/3/1984, por leituras visuais, através de uma escala de notas (DUDIENAS et alii, 1984) variando de 1 a 5 , sendo 1 para plantas com 0 a $10 \%$ de área foliar afetada, 2 para 11 a $20 \%, 3$ para 21 a $30 \%, 4$ para 31 a $40 \%$ e 5 acima de $40 \%$. 
A classificação dos tipos de reação foi efetuada, considerando-se resistente (R) - notas 1 e 2, intermediário (I) - nota 3, e suscetível (S) - notas 4 e 5 .

\section{RESULTADOS E DISCUSSAO}

No quadro 1, onde são apresentadas as reaçסes dos cultivares de so ja, observa-se que IAC-9 e IAC-10 foram suscetíveis, IAC-8 e IAC-12 comportaram-se como intermediários, e Cristalina e IAC-11 foram resistentes.

QUADRO 1 - Reação dos cultivares de soja a Cercospora sojina Hara, nas diferentes épocas de plantio

\begin{tabular}{|c|c|c|c|c|c|c|}
\hline \multirow{2}{*}{ Cultivar } & \multirow{2}{*}{ Origem } & \multicolumn{4}{|c|}{ Época $\left({ }^{1}\right)$} & \multirow{2}{*}{ Média $\left({ }^{1}\right)$} \\
\hline & & $1^{\mathrm{a}}$ & 2 . & $3^{\mathbf{a}}$ & 4 & \\
\hline Cristalina $\left({ }^{2}\right)$ & Davis $\mathrm{x}$ UFV-1 & $\mathbf{R}$ & $\mathbf{R}$ & $\mathbf{R}$ & $\mathbf{R}$ & $\mathbf{R}$ \\
\hline $\operatorname{IAC}-11\left({ }^{2}\right)$ & Paraná X F1 (Davis x IAC-73-1364) & $\mathbf{R}$ & $\mathbf{R}$ & $\mathbf{R}$ & $\mathbf{R}$ & $\mathbf{R}$ \\
\hline IAC-8 & Bragg x E 70-51 & I & $\mathbf{I}$ & I & I & $\mathbf{I}$ \\
\hline IAC-12 & Paraná x IAC 73-231 & $\mathbf{R}$ & $\mathbf{I}$ & I & $\mathbf{R}$ & I \\
\hline IAC-9 & Seleção na populaçăo RB 721 & $\mathbf{s}$ & $\mathbf{S}$ & $\mathbf{S}$ & $\mathbf{I}$ & $\mathbf{S}$ \\
\hline IAC-10 & Hardee $\mathrm{x}$ Hill & $\mathbf{S}$ & $\mathbf{S}$ & $\mathbf{S}$ & $S$ & $\mathrm{~S}$ \\
\hline
\end{tabular}

( ${ }^{1}$ ) Reação: R: resistente; I: intermediária; S: suscetível.

$\left({ }^{2}\right)$ Ausência de sintomas, com algumas plantas suscetiveis.

Nos cultivares Cristalina, IAC-8, IAC-10 e IAC-11, a reação foi igual para todas as épocas de plantio. O IAC-9 apresentou a mesma reação, $\mathrm{S}$, nas três primeiras épocas, sendo que a reação I, na quarta, pode ser devida a estarem as plantas ainda muito jovens, pois o cultivar é mais tardio. $O$ IAC-12 não apresentou reaçðes bem definidas, variando de suscetível a resistente dentro das épocas: assim, aparentemente, não houve efeito de época de plantio.

Nos cultivares Cristalina e IAC-11, em que não houve incidência de C. sojina, foram encontradas apenas algumas plantas isoladas com sintomas 
da doença: na primeira época, uma planta de Cristalina e duas de IAC-11; na segunda, três plantas de IAC-11; na terceira, seis plantas de IAC-11, sendo que duas delas em associação com uma virose não identificada; e, na quarta época, três plantas de IAC-11, sendo duas em associação com virose. Essa mistura de plantas com reaços variando de resistente a altamente suscetível foi observada por YORINORI (1984), em oito cultivares brasileiros de soja. Assume-se que os cultivares resistentes, nos quais houve incidência da doença, não são homogêneos quanto a essa característica.

Desconsiderando as poucas plantas que apresentaram sintomas, a reação apresentada por Cristalina concorda com o resultado obtido por ROCHA et alii (1984); contudo, o comportamento de IAC-8 diferiu, pois- neste experimento foi classificado como intermediário, e aqueles autores não observaram sintomas quando o inocularam com um isolado de $C$. sojina proveniente do Rio Paranaíba (MG). Como este patógeno apresenta especialização fisiológica, observada pela primeira vez por ATHOW et alii (1962), pode ser que estejam envolvidas diferentes raças, resultando assim em diferentes reações das plantas.

Pela genealogia (Quadro 1), pode-se pressupor que a resistência observada no cultivar Cristalina seja proveniente do 'Davis', apontado como resistente às quatro raças de $C$. sojina existentes nos EUA, por ROOS (1968), e também aos isolados obtidos no Brasil em diferentes locais (VEIGA, 1973, e YORINORI, 1982). A resistência de IAC-11 pode ter origem tanto no 'Davis' quanto no 'Paraná', ou em ambos.

A alta incidencia desta doença em Ribeirão Preto deve ter sido ocasionada pela utilização da mesma área, ano após ano, com esta cultura, aumentando o potencial de inóculo do fungo, que deve ter sido introduzido através de sementes contaminadas, um dos veículos de disseminação do patógeno. Assume, portanto, importância a eliminação de plantas suscetíveis, dentro de cultivares resistentes, principalmente em campos destinados à produção de sementes, evitando, assim, a introdução do patógeno em novas áreas e diminuindo a possibilidade do aparecimento de novas raças, às quais o cultivar nāo apresenta resistência.

\section{SUMMARY}

\section{INCIDENCE OF CERCOSPORA SOINA HARA ON SOYBEAN CULTIVARS}

The reaction of 6 soybean cultivars to frogeye (Cercospora sojina Hara) was evaluated under field conditions, using a scale of notes varying from 1 to 5 , being 1 for minimum infection and 5 for maximum infection. Cultivars IAC- 9 and IAC-10 were susceptible; IAC-8 and IAC-12 were intermediate; and Cristalina and IAC-11 were resistant. Even the resistant cultivars had a few plants infected. Taking this into account and considering the potential risk of this disease, roguing is recommended mainly in seed production fields.

Index terms: Cercospora sojina; soybean; resistance. 


\section{REFERENCIAS BIBLIOGRAFICAS}

ATHOW, K.L.; PROBST, A.H.; KURTZMAN, C.P. \& LAVIOLETTE, F.A. A newly identified physiological race of Cercospora sojina Hara on soybean. Phy topathology, 52:712-714, 1962.

COSTA, A.S. Investigação sobre moléstias da soja no Estado de São Paulo. Summa Phytopathologica, Piracicaba, 3: 3-30, 1977.

DUDIENAS, C.; ITO, M.F.; \& BENATTI JÚNIOR, R. Comportamento de diferentes cultivares de rami (Boehmeria nivea Gaudich.) quanto a manchas foliares causadas por Cercospora krugiana Muller \& Chupp, em condiçðes de campo. Fitopatologia Brasileira, Brasília, 9:551-554, 1984.

ROCHA, V.S. ; GOMES, J.L.L.; SEDIYAMA, T.; SEDIYAMA, C.S. \& ATHOW K.L. Avaliação da resistência de cultivares de soja adaptadas às regiðes Sul e Sudeste, a dois isolados de Cercospora sojina Hara. In: SEMINÁRIONACIONAL DE PESQUISA DE SOJA, 3., Campinas, 1984. Resumos. p.31.

ROOS, J.P. Additional physiological races of Cercospora sojina on soybeans in North Carolina. Phytopathology, 58:708-709, 1968.

VEIGA, P. Cercospora sojina Hara: obtenção do inóculo e avaliação da resistência em soja (Glycine max (L.) Merrill). Piracicaba, Escola Superior de Agricultura "Luiz de Queiroz", 1973. 45p. Tese. (Mestrado)

YORINORI, J.T. Doenças da soja no Brassil. In: A SOJA no Brasil Central. ed. rev. ampl. Campinas, Fundação Cargill, 1982. p.301-345.

. Reação das cultivares brasileiras de soja a Cercospora sojina Hara. In:SEMINÁRIO NACIONAL DE PESQUISA DE SOJA, 3., Campinas, 1984. Resumos. p.30.

\& GARCIA, A. Danos causados por Cercospora sojina Hara nas sementes do cultivar de soja Bragg. Fitopatologia Brasileira, Brasília, 2: 107-108, 1977. (Resumo) 